\title{
Effects of 12 weeks of aerobic training on autonomic modulation, mucociliary clearance, and aerobic parameters in patients with COPD
}

This article was published in the following Dove Press journal:

International Journal of COPD

23 November 2015

Number of times this article has been viewed

\author{
Marceli Rocha Leite' \\ Ercy Mara Cipulo Ramos' \\ Carlos Augusto Kalva-Filho² \\ Ana Paula Coelho Figueira \\ Freire' \\ Bruna Spolador de Alencar \\ Silva' \\ Juliana Nicolino' \\ Alessandra Choqueta de \\ Toledo-Arruda ${ }^{3}$ \\ Marcelo Papoti ${ }^{4}$ \\ Luiz Carlos Marques \\ Vanderlei' \\ Dionei Ramos' \\ 'Department of Physiotherapy, São \\ Paulo State University, Presidente \\ Prudente, ${ }^{2}$ Program in Rehabilitation \\ and Functional Performance, São \\ Paulo University, Ribeirão Preto, \\ ${ }^{3}$ Department of Medicine, São \\ Paulo University, ${ }^{4}$ School of Physical \\ Education and Sport of Ribeirão \\ Preto, São Paulo University, Ribeirão \\ Preto, São Paulo, Brazil
}

Introduction: Patients with chronic obstructive pulmonary disease (COPD) exhibit aerobic function, autonomic nervous system, and mucociliary clearance alterations. These parameters can be attenuated by aerobic training, which can be applied with continuous or interval efforts. However, the possible effects of aerobic training, using progressively both continuous and interval sessions (ie, linear periodization), require further investigation.

Aim: To analyze the effects of 12-week aerobic training using continuous and interval sessions on autonomic modulation, mucociliary clearance, and aerobic function in patients with COPD.

Methods: Sixteen patients with COPD were divided into an aerobic (continuous and interval) training group (AT) $(n=10)$ and a control group $(C G)(n=6)$. An incremental test (initial speed of $2.0 \mathrm{~km} \cdot \mathrm{h}^{-1}$, constant slope of $3 \%$, and increments of $0.5 \mathrm{~km} \cdot \mathrm{h}^{-1}$ every 2 minutes) was performed. The training group underwent training for 4 weeks at $60 \%$ of the peak velocity reached in the incremental test $\left(\mathrm{VVO}_{2 \text { peak }}\right)$ ( 50 minutes of continuous effort), followed by 4 weeks of sessions at $75 \%$ of $\mathrm{vVO}_{2 \text { peak }}(30$ minutes of continuous effort $)$, and 4 weeks of interval training $(5 \times 3$-minute effort at $\mathrm{vVO}_{2 \text { peak }}$, separated by 1 minute of passive recovery). Intensities were adjusted through an incremental test performed at the end of each period.

Results: The AT presented an increase in the high frequency index $\left(\mathrm{ms}^{2}\right)(P=0.04)$, peak oxygen uptake $\left(\mathrm{VO}_{2 \text { peak }}\right)(P=0.01), \mathrm{vVO}_{2 \text { peak }}(P=0.04)$, and anaerobic threshold $(P=0.02)$. No significant changes were observed in the CG $(P>0.21)$ group. Neither of the groups presented changes in mucociliary clearance after 12 weeks (AT: $P=0.94$ and CG: $P=0.69$ ).

Conclusion: Twelve weeks of aerobic training (continuous and interval sessions) positively influenced the autonomic modulation and aerobic parameters in patients with COPD. However, mucociliary clearance was not affected by aerobic training.

Keywords: COPD, exercise, aerobic treatment, mucociliary clearance

\section{Introduction}

Although various training modalities can be applied in patients with chronic obstructive pulmonary disease (COPD) (eg, resistance, in-water, and tai chi), aerobic stimulus has been investigated in several studies, predominantly due to the ease of application, prescription and, consequently, monitoring of this training modality. ${ }^{1}$ Aerobic training provides clear improvement in the quality of life and increases in aerobic parameters and functional capacity, thereby improving factors such as dyspnea, exercise intolerance, and reduced quality of life, which are common symptoms in patients with COPD. ${ }^{1-3}$

Mucociliary clearance is deficient in patients with $\mathrm{COPD}^{4,5}$ mainly due to mucus hypersecretion, which is related to a significant decrease in forced expiratory volume in
Correspondence: Marceli Rocha Leite Departamento de Fisioterapia, Universidade Estadual Paulista, Rua Roberto Simonsen, Number 305 Presidente Prudente, SP 19060-900, Brazil

Email marcelirocha@hotmail.com 
the first second and severe coughing. This situation increases the risk of hospitalization. ${ }^{6}$ Improvements in mucociliary clearance have been observed after acute aerobic stimulus, but the chronic effects are still controversial in healthy individuals. ${ }^{7,8}$ Although knowledge about the response of mucociliary clearance to aerobic stimulus appears to be extremely important, no studies have investigated this parameter longitudinally in patients with COPD.

Aerobic training has been related to significant improvements in autonomic modulation, suggesting better adaptation and efficiency of the cardiovascular system. ${ }^{9,10}$ In addition, relations between autonomic control and aerobic variables were also observed acutely in COPD patients, ${ }^{11}$ highlighting that good aerobic conditioning is related to an increase in the vagal activity of heart rate control. However, the possible effects of different aerobic models on autonomic control remain unclear.

In this context, aerobic training in patients with COPD can be performed with continuous or interval efforts. ${ }^{1,12}$ Continuous efforts are frequently applied 3-4 times per week, with different intensities and durations, whereas interval training sessions are applied 2-3 times per week, using effort periods lasting 30-180 seconds, separated by passive or active recovery. When these aerobic training modalities (ie, continuous and interval) are applied separately, the training adaptations appear to be similar in patients with COPD. ${ }^{12}$

Moreover, to our knowledge, no studies have investigated the use of continuous and interval sessions in the same periodization in patients with COPD. This approach may be more effective, principally by enabling the adaptations related to both models of aerobic training stimulus (ie, continuous and interval).

In summary, aerobic exercise can be considered a good intervention in pulmonary rehabilitation, but more studies on mucociliary clearance responses and autonomic control adaptations from aerobic training are necessary, specifically when training is applied with continuous and interval stimulus in the same periodization. Thus, the aim of this study was to investigate the effects of a 12-week aerobic training protocol with continuous and interval sessions on autonomic modulation, mucociliary clearance, and aerobic parameters in patients with COPD.

\section{Material and methods}

\section{Setting and participants}

This study was characterized as a nonrandomized clinical trial which considered the effects of 12 weeks of aerobic training on autonomic modulation (evaluated through heart rate variability [HRV]), mucociliary clearance, and aerobic function in patients with COPD, according to the criteria established by the Global Initiative for Obstructive Lung Disease (GOLD). ${ }^{13}$

The study was conducted in a public rehabilitation center, and patients presenting any of the following conditions were excluded: 1) not having been in smoking cessation for at least 1 year; 2) the presence of severe pathological conditions and/ or unstable heart diseases that could influence the physical activity; 3) presenting diseases that could interfere in the systemic inflammatory process; 4) unstable COPD (ie, exacerbations and medication changes in the previous 30 days); 5) the use of home oxygen therapy; and 6) individuals who had performed any kind of physical training program before participating in this study.

The initial evaluation was performed in 31 patients, after which they were divided into two separate groups: an aerobic training group (AT) and a control group (CG).

The CG consisted of ten patients who chose not to participate in the training protocol due to transportation difficulties in arriving at the rehabilitation center, living in faraway places, or not being able to attend the 3-day weekly training. Among them, four patients did not attend the final evaluations, one due to exacerbation and three patients for personal reasons. The aerobic training protocol started with 21 patients, eleven of whom did not complete the 12 -week protocol as five patients exacerbated and six gave up for personal reasons (Figure 1).

Medications used by the patients during the study were: $\beta_{2}$ agonists $(n=12)$, anticholinergics $(n=6)$, diuretics $(n=4)$, antagonists of angiotensin receptors $(n=5), \beta$-blockers $(n=1)$, benzodiazepines $(n=1)$.

All participants were previously informed about the procedures and aims of this study, and signed a consent form. All procedures utilized in this study were approved by the Institutional Ethics Research Committee (CAAE: 01114912.0.0000.5402).

\section{Design overview}

The experimental protocol consisted of patient identification, anthropometric evaluation, pulmonary function through spirometry, a cardiopulmonary test, evaluation of autonomic function by HRV, a mucociliary clearance test using the saccharin transit time (STT) test, and realization of 12 weeks of aerobic training. The participants were conventionally divided into AT and no-training CG. Evaluation periods were performed at baseline (M0) and after 12 weeks (M1) for both groups. 


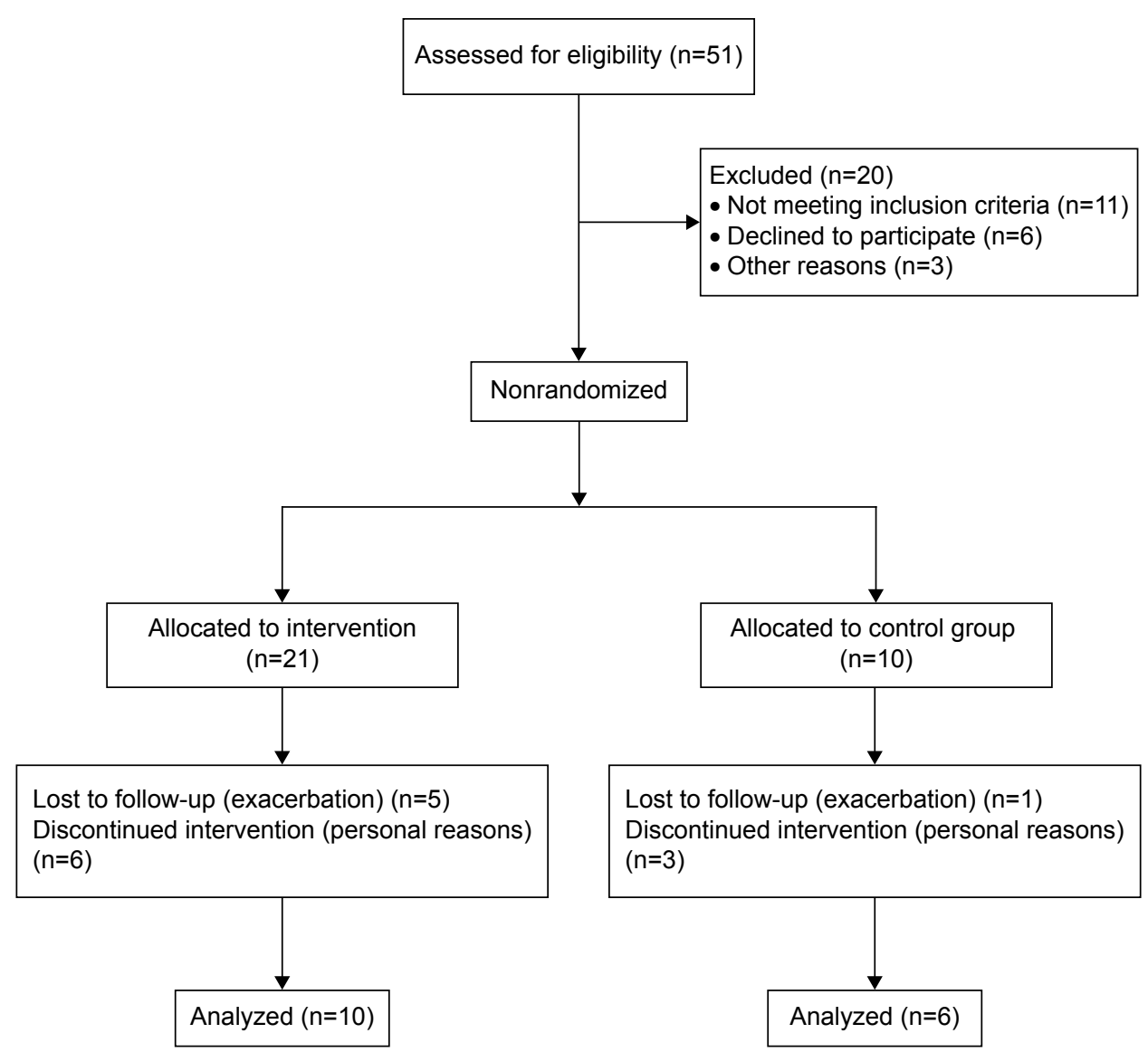

Figure I Flow diagram showing the participation of the patients in the study.

To minimize interference with circadian rhythm and external factors, evaluations were individually performed in a room with temperature ranging from $21^{\circ} \mathrm{C}$ to $23^{\circ} \mathrm{C}^{9}$ and relative humidity between $50 \%$ and $60 \%$, always in the morning period between 8 am and $12 \mathrm{pm}$. Final assessments were performed between 24 and 48 hours after the final training session.

For all sessions, patients were instructed to: 1) avoid consuming caffeine for 24 hours before procedures; 2) eat a light meal 2 hours before the tests; 3) avoid drinking alcoholic beverages for at least 4 hours; 4) avoid strenuous physical exercises the day prior to the session; and 5) wear suitable and comfortable clothes for physical exercises.

\section{Anthropometric assessment}

Body weight and height were measured to obtain body mass index through the following formula: body weight (in kilograms) divided by height ${ }^{2}$ (meters). The measurements were performed using a digital scale (Welmy R/I 200, Welmy, Sao Paulo, Brazil) according to the recommendations described by Lohman et al. ${ }^{14}$

\section{Pulmonary function assessment}

Pulmonary function assessment was carried out by a spirometry test (MIR-Spirobank 3.6 version spirometer; MIR, Rome, Italy). The results were interpreted according to the American Thoracic Society and European Respiratory Society rules. ${ }^{15}$ Normality values were related to the Brazilian population. ${ }^{16}$

\section{Evaluation of aerobic function}

For the prescription of aerobic exercise and evaluation of aerobic function, patients performed a maximal cardiopulmonary exercise test (Inbrasport ATL 2000; Inbrasport, Rio Grande do Sul, Brazil) with an initial speed of $2.0 \mathrm{~km} \cdot \mathrm{h}^{-1}$, constant slope of $3 \%$, and increments of $0.5 \mathrm{~km} \cdot \mathrm{h}^{-1}$ every 2 minutes. The test was performed until voluntary exhaustion was reached. ${ }^{17}$ None of the patients presented clinical or electrocardiographic changes that prevented them from finishing the test. The cardiopulmonary test was repeated every 4 weeks in order to adjust session intensity.

The following variables were monitored continuously: 1) heart rate (Polar S810i, Polar Electro, Kempele, Finland); 
2) arterial oxygen saturation $\left(\mathrm{SpO}_{2} \%\right)$ (Mindray PM 50 Oximeter, Mindray, Sao Paulo, Brazil); and 3) subjective perception of effort. ${ }^{18}$ Furthermore, ventilatory variables were obtained through the gas analyzer (VO2000, Medical Graphics, St. Paul, MN, USA), which was calibrated before every test according to the supplier's specifications. The flow of average air was utilized in all tests, and gas samples were obtained every 10 seconds (Aerograph ${ }^{\circledR}$, MI, USA).

The peak oxygen uptake $\left(\mathrm{VO}_{\text {2peak }}\right)$ was considered the highest oxygen consumption average of the final 30 seconds of the exercise $\left(\mathrm{VO}_{2}\right)$. The speed related to $\mathrm{VO}_{\text {2peak }}\left(\mathrm{VVO}_{\text {2peak }}\right)$ was considered to be the highest intensity reached during the test. In cases where the patient demonstrated exhaustion before the end of the stage, the $\mathrm{vVO}_{2 \text { peak }}$ was adjusted by the equation proposed by Kuipers et al. ${ }^{19}$ Moreover, the gas exchange threshold (GET) was determined using the V-Slope method, described by Sue et $\mathrm{a}^{20}$ for COPD patients. In the present study, the breakpoint of the $\mathrm{VCO}_{2}-\mathrm{VO}_{2}$ relationship was assumed as the GET, observed during the incremental test.

\section{Evaluation of autonomic modulation}

For the HRV analysis, heart rate was captured beat by beat through a heart rate monitor, Polar S810i (Polar Electro), which had been properly validated. ${ }^{21}$

After explaining the necessary procedures for data collection, an elastic strap was positioned on the chest of each patient at the xiphoid process, and a heart rate receiver was placed on the wrist (Polar Electro). Heart rate at rest was recorded for 20 minutes with the patient in a seated position.

For the analysis of HRV indexes, 256 consecutive RR intervals were used. They were selected from the most stable portion and, in order to eliminate premature ectopic beats and artifacts, were submitted to digital filtering through Polar Precision Performance SW Software (version 4.01.029) supplemented by manual procedures. Only series with more than $95 \%$ sinus beats were included in this study. ${ }^{22,23}$

Indexes in the time and frequency domains were calculated. In the time domain, the following indexes were used: standard deviation of normal RR intervals (SDNN), expressed in milliseconds, and root mean square of the difference between the adjacent normal RR intervals in a time interval (RMSSD), expressed in milliseconds. ${ }^{22,24}$ For HRV analysis in the frequency domain, low frequency (LF: 0.04-0.15 Hz) and high frequency (HF: 0.15-0.4 Hz) spectral components were used, in $\mathrm{ms}^{2}$ and normalized units (nu), which represent the relative value of each spectral component in relation to total power, less the very low frequency component and the ratio between these components (LF/HF ratio). ${ }^{22,24}$ In order to calculate these indexes, Kubios version 2.0 Software ${ }^{25}$ was used.

\section{Evaluation of nasal mucociliary clearance}

For mucociliary clearance evaluation, the patients were seated with their heads in a straight position at $10^{\circ}$. The STT started with the introduction of $\sim 2.5 \mathrm{mg}$ of granulated saccharin sodium through a plastic straw, under visual control, $\sim 2 \mathrm{~cm}$ into the right nostril. At this moment, the timer was started, and patients were instructed not to walk, talk, cough, sneeze, scratch, or blow their nose. They were also instructed to swallow as little as possible until they could feel the flavor in their mouth. At this point, the patient advised the examiner, who then registered the time. ${ }^{26-28}$ For the STT at baseline condition, the patients remained at rest for 20 minutes before starting the test in order to minimize the effects of the external environment on the nasal ciliary beat.

\section{Periodized aerobic training}

All sessions were performed on a treadmill (Inbrasport ATL 2000, Porto Alegre, Brazil). The aerobic training was composed of three training mesocycles, each lasting 4 weeks. The frequency of the sessions was three times per week.

The training sessions were divided into three intensity zones: $\mathrm{Z1}$ : 50-minute sessions at an intensity corresponding to $60 \%$ of $\mathrm{vVO}_{2 \text { peak }}$ (continuous effort); Z2: 30 -minute sessions at an intensity corresponding to $75 \%$ of $\mathrm{vVO}_{2 \text { peak }}$ (continuous effort); and Z3: formed by five efforts of 3 minutes performed at $100 \%$ of $\mathrm{vVO}_{2 \text { peak }}$, separated by 1 minute of passive recovery (interval effort). The intensity of each mesocycle was adjusted according to the incremental test performed every 4 weeks.

The first training mesocycle predominated in the sessions Z1 (85.9\% of total sessions; 344 minutes), with a shorter time in Z2 (14.1\% of total sessions; 57 minutes). In the second mesocycle, sessions were applied in Z1 (34.5\% of total sessions; 138 minutes), but the predominance was in $\mathrm{Z} 2$ ( $65.5 \%$ of total volume; 262 minutes). The third mesocycle had sessions in Z2 (32.5\% of total volume; 130 minutes) with predominance in $\mathrm{Z3}$ (67.5\% of total volume; 270 minutes). Thus, COPD patients performed 1091 minutes of aerobic training. The intensity and different session durations between mesocycles were chosen on the basis of previously published studies. ${ }^{29-31}$ Figure 2 demonstrates the time spent in each intensity zone during the 12 -week aerobic training protocol. 


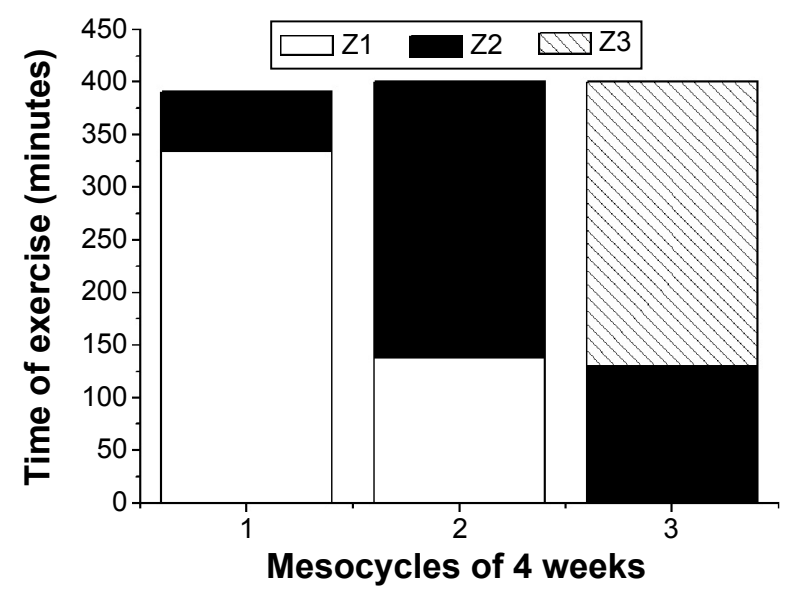

Figure 2 Time spent in each intensity zone during the 12 weeks of aerobic training. Notes: $\mathrm{ZI}: 60 \%$ of $\mathrm{VO}_{2 \text { peak }}$ for 50 minutes (continuous effort); $\mathrm{Z2}: 75 \%$ of $\mathrm{VO}_{2 \text { peak }}$ for 30 minutes (continuous effort); Z3: five efforts lasting 3 minutes separated by I minute of passive recovery (interval effort).

Abbreviation: $\mathrm{VO}_{2 \text { peak }}$, peak oxygen uptake.

\section{Statistical analysis}

Initially, the analysis of data normality was performed and certified by the Shapiro-Wilk test. Asymmetric distribution was observed for $\mathrm{VO}_{2 \text { peak }}$, normalized by weight ( $\mathrm{M} 0$ in both AT and CG; $P<0.01$ ), $\mathrm{vVO}_{2 \text { peak }}$ (M0 in AT; $P=0.04$ ), velocity at GET (M0 in CG; $P=0.04$ ), and RMSSD (M0 in $\mathrm{CG} ; P=0.03)$. Logarithmic transformation did not correct the asymmetry. Thus, all variables were presented as median (interquartile range). Differences between groups at M0 were evidenced by the Student $t$-test for independent samples (normally distributed variables) and by the Mann-Whitney test for asymmetric variables. Moreover, differences between evaluations (ie, M0 vs M1) were evidenced by the Student $t$-test for dependent samples (normally distributed variables) and by the Wilcoxon test for asymmetric variables. The Statistical Package for Social Science software, version 17.0 (SPSS Inc, Chicago, IL, USA) was used, and the level of significance was $P<0.05$.

\section{Results}

Sixteen patients with COPD were included in this study. The AT group was composed of ten patients (GOLD II Moderate COPD: $n=7$, GOLD III Severe COPD: $n=3$ ), and the CG of six patients (GOLD I Mild COPD: $n=1$, GOLD II Moderate COPD: $n=2$, GOLD III Severe COPD: $n=4)$.

Table 1 demonstrates that there were no differences between the evaluated groups in relation to anthropometric data and pulmonary function.

Table 2 demonstrates the aerobic parameters observed at M0 and M1 for both groups. No significant differences were observed between the AT and the CG at M0 $(P>0.37)$.
Table I Anthropometric data and pulmonary function of the assessed patients expressed in median (interquartile range 25\%-75\%)

\begin{tabular}{|c|c|c|c|}
\hline & AT $(n=10)$ & CG $(n=6)$ & $P$-value \\
\hline Age (years) & $62(60.25-69.25)$ & $62.5(57.25-70.5)$ & 0.8543 \\
\hline \multicolumn{4}{|l|}{ Anthropometric } \\
\hline Height $(\mathrm{cm})$ & $165(154.3-173)$ & $165(157-168.5)$ & 0.9851 \\
\hline Weight (kg) & $74.4(64-87)$ & $70.7(65.25-78)$ & 0.5102 \\
\hline BMI $\left(\mathrm{kg} \cdot\left[\mathrm{m}^{2}\right]^{-1}\right)$ & $27.6(21.83-32.54)$ & $26.85(23-30.88)$ & 0.9578 \\
\hline \multicolumn{4}{|l|}{ Spirometrics } \\
\hline $\mathrm{FEV}_{1}$ (\%pred) & 55 (39-70) & $45(37.65-73.63)$ & 0.8749 \\
\hline FVC (\%pred) & $78(66.25-83.48)$ & $86.61(61.8-101.8)$ & 0.7925 \\
\hline $\mathrm{FEV}_{1} / \mathrm{FVC}$ & $56(46.78-65.7)$ & $48.1(41.1-66.05)$ & 0.5104 \\
\hline
\end{tabular}

Abbreviations: AT, aerobic training group; CG, control group; BMI, body mass index; FEV ${ }_{1}$, forced expiratory volume in the first second; FVC, forced vital capacity; (\%pred), percentage of predicted values.

All aerobic variables increased significantly after 12 weeks for the AT group $(P<0.03)$, but no differences were observed for the $\mathrm{CG}(P>0.21)$. At M1, the AT group presented higher values compared to the $\mathrm{CG}$ for $\mathrm{VO}_{2 \text { peak }}$ (absolute and relative to weight values; $P=0.02$ and 0.01 , respectively), $\mathrm{vVO}_{2 \text { peak }}$ $(P=0.04)$, and $\mathrm{VO}_{2}$ observed at $\operatorname{GET}(P=0.01)$.

Table 3 shows the results of autonomic modulation evaluation in the time and frequency domains. No differences between groups were observed at M0 $(P>0.71)$. An increase in the HF (ms) index after 12 weeks can be observed in the AT $(P=0.042)$. However, although a tendency was observed for RMSSD $(P=0.08)$, there was no difference for the other HRV parameters $(P>0.13)$ in the AT group. No significant differences were observed in the CG $(P>0.31)$. Moreover, no differences were observed between the groups at $\mathrm{M} 1(P>0.08)$.

Figure 3 shows the values of STT between the groups at M0 and M1. No differences were observed between the groups at M0 $(P=0.61)$. In addition, no changes were observed during 12 weeks either in the AT $(P=0.94)$ or in the CG $(P=0.69)$ group. Values were similar between the groups at $\mathrm{M} 1(P=0.12)$.

\section{Discussion}

The main findings of this study demonstrate that 12 weeks of aerobic training applied with continuous and interval sessions induced a significant increase in aerobic parameters obtained through an incremental test. Moreover, a positive influence on autonomic modulation was observed, evidenced by a significant increase in parasympathetic modulation. However, no improvement was observed in the STT after aerobic training.

$\mathrm{VO}_{2 \text { peak }}$ is considered an index of maximum aerobic power, while $\mathrm{VVO}_{2 \text { peak }}$ can be seen as the index that better 
Table 2 Aerobic parameters of aerobic training group (AT) and control group (CG), observed at baseline (M0) and after 12 weeks (MI) expressed in median (interquartile range 25\%-75\%)

\begin{tabular}{|c|c|c|c|c|}
\hline & \multicolumn{2}{|l|}{ AT $(n=10)$} & \multicolumn{2}{|l|}{ CG $(n=6)$} \\
\hline & Mo & MI & Mo & MI \\
\hline $\mathrm{VO}_{2 \text { peak }}\left(\mathrm{L} \cdot \mathrm{min}^{-1}\right)$ & $0.63(0.4-1)$ & $1.83(1.3-2.7)^{* * * *}$ & $0.56(0.5-0.5)$ & $0.6(0.4-0.3)$ \\
\hline $\mathrm{VO}_{2 \text { peak }}\left(\mathrm{mL} \cdot \mathrm{kg}^{-1} \cdot \mathrm{min}^{-1}\right)$ & $10(6.2-13)$ & $26.28(14.9-33.6)^{* * * * *}$ & $7.7(7.6-7.5)$ & $7.9(6.1-3.9)$ \\
\hline $\mathrm{vVO}_{2 \text { peak }}\left(\mathrm{km} \cdot \mathrm{h}^{-1}\right)$ & $6(4.2-6.4)$ & $6.4(5.2-7.5)^{* * * *}$ & $4.8(4.5-4.5)$ & $4.5(4-3.2)$ \\
\hline $\operatorname{GET}\left(\mathrm{km} \cdot \mathrm{h}^{-1}\right)$ & $3.25(2.6-3.5)$ & $4.5(3.1-4.9)^{*}$ & $3.0(3-2.5)$ & $3.0(3-2.5)$ \\
\hline GET $\left(\mathrm{mL} \cdot \mathrm{kg}^{-1} \cdot \mathrm{min}^{-1}\right)$ & $0.34(0.2-0.6)$ & $0.9(0.7-1.8)^{* * * *}$ & $0.4(0.3-0.3)$ & $0.3(0.3-0.2)$ \\
\hline
\end{tabular}

Notes: *Significant difference between M0 and MI $(P<0.05)$; **significant difference between AT and CG at MI.

Abbreviations: $\mathrm{VO}_{2 \text { peak }}$, peak oxygen uptake; $\mathrm{VVO}_{2 \text { peak }}$, velocity corresponding to $\mathrm{VO}_{\text {2peak }} ; \mathrm{GET}$, gas exchange threshold.

represents the association between aerobic power and movement economy. ${ }^{32}$ GET is an important submaximal aerobic variable, mainly because it represents the highest intensity where lactate presents equilibrium in the blood. ${ }^{33}$ In addition, this index is frequently used in training prescription, monitoring, and performance prediction. ${ }^{34,35}$ Several studies have demonstrated improvement in these parameters after execution of aerobic training, ${ }^{9,36-38}$ which is essential in all COPD stages due to its capacity to reduce dyspnea, improve functional capacity, and offer better quality of life for these patients. ${ }^{2,3}$

In this study, an important improvement in all aerobic variables was observed after the aerobic training. Although on a smaller scale, a similar response was found in studies that applied traditional training methods..$^{9,36-38}$

It was also observed that after 12 weeks of aerobic training, there was a significant increase in HF (ms), which represents the parasympathetic component of autonomic modulation. ${ }^{39}$ In relation to other evaluated indices, no significant difference was observed before or after training. However, it was observed that HF (nu) increased after 12 weeks in the AT and the LF (nu) index was reduced in relation to the $\mathrm{LF} / \mathrm{HF}$ ratio, representing an increase in parasympathetic activity, a reduction in sympathetic activity, and an improvement in the sympathetic-vagal balance. These data indicate that there was a positive impact on autonomic modulation in patients submitted to periodized aerobic training, suggesting better adaptation and efficiency of the cardiovascular system in these patients, considering the environmental and physiological stimulus required at every moment of daily life activities. This includes better respiratory capacity and performance responses during physical activity, which is essential to the rehabilitation process in the COPD population..$^{39}$

Previous studies have also shown significant improvements in autonomic modulation after completion of physical

Table 3 Heart rate variability indexes of aerobic training group (AT) and control group (CG), observed at baseline (M0) and after 12 weeks (MI) expressed in median (interquartile range $25 \%-75 \%$ )

\begin{tabular}{|c|c|c|c|c|}
\hline & \multicolumn{2}{|l|}{ AT $(n=10)$} & \multicolumn{2}{|l|}{ CG $(n=6)$} \\
\hline & Mo & MI & Mo & MI \\
\hline \multirow[t]{2}{*}{ SDNN (ms) } & $19.84 \pm 6.21$ & $24.87 \pm 8.6$ & $19.17 \pm 4.95$ & $18.9 \pm 5.7$ \\
\hline & $20.35(\mid 4.7-25.23)$ & $25(20.08-32.55)$ & I8.9 (I5.28-23.53) & $19.25(13.13-24.25)$ \\
\hline \multirow[t]{2}{*}{ RMSSD (ms) } & $14.15 \pm 5.69$ & $18.28 \pm 6.22$ & $13.47 \pm 7.89$ & $15.02 \pm 8.12$ \\
\hline & 14.15 (9.15-20.3) & 20.05 (13.73-22.98) & $12.65(7.1-16.88)$ & $12.25(10-20.78)$ \\
\hline \multirow[t]{2}{*}{$\operatorname{LF}\left(\mathrm{ms}^{2}\right)$} & $|46.1 \pm| \mid 8.9$ & $177.7 \pm 125.6$ & $130.7 \pm 49$ & $10 \mathrm{I} \pm 40.36$ \\
\hline & $97.5(56-237.8)$ & $161.5(79.5-267.8)$ & $12 \mid(86.5-174.5)$ & $92.5(7 I-125.8)$ \\
\hline \multirow[t]{2}{*}{ LF (nu) } & $67.47 \pm 15.96$ & $58.48 \pm 13.62$ & $69.65 \pm 19.8$ & $66.43 \pm 16.36$ \\
\hline & 70.8 (55-79) & $57.75(52.8-70.4)$ & 72.1 (49.4-87.83) & $64.05(52.03-83.25)$ \\
\hline \multirow[t]{2}{*}{$\mathrm{HF}\left(\mathrm{ms}^{2}\right)$} & $62.3 \pm 46.84$ & $113.2 \pm 62.19 *$ & $60.17 \pm 39.98$ & $61.17 \pm 48.33$ \\
\hline & $49.5(20-107.5)$ & $109(66.25-158.8)$ & $69(15.25-93)$ & $53.5(16.75-105.3)$ \\
\hline \multirow[t]{2}{*}{$\mathrm{HF}(\mathrm{nu})$} & $32.63 \pm 15.9$ & $41.52 \pm 13.62$ & $30.35 \pm 19.8$ & $33.57 \pm 16.36$ \\
\hline & $29.7(20.75-44.3)$ & $42.25(29.6-47.2)$ & $27.9(12.18-50.6)$ & $35.95(16.75-47.98)$ \\
\hline \multirow[t]{2}{*}{$\mathrm{LF} / \mathrm{HF}$} & $2.9 \pm 2.2$ & $1.62 \pm 0.77$ & $4.5 \pm 4.79$ & $2.91 \pm 2.43$ \\
\hline & $2.5(1.2-3.8)$ & $1.36(1.12-2.37)$ & $2.82(0.98-7.97)$ & $1.91(1.09-5.14)$ \\
\hline
\end{tabular}

Note: *Significant difference between M0 and MI $(P<0.05)$.

Abbreviations: SDNN, standard deviation of the mean of all normal RR intervals; RMSSD, root mean square of differences between adjacent normal RR intervals in a time interval; LF, spectral component of low frequency; HF, spectral component of high frequency; nu, normalized units. 


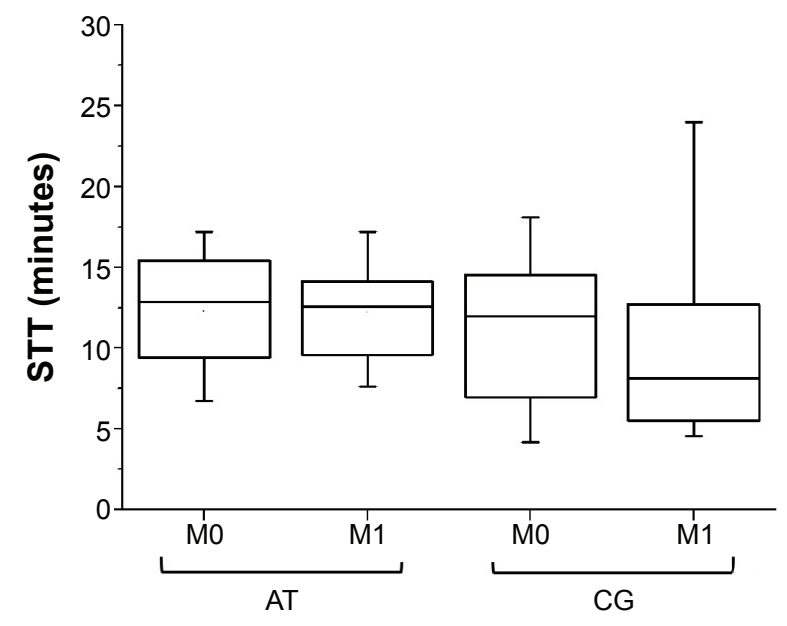

Figure 3 Box plot of saccharin transit time (STT) test of the aerobic training group (AT) and the no-training control group (CG), observed at baseline (M0) and after 12 weeks $(\mathrm{MI})$

training in patients with COPD. Camillo et $\mathrm{al}^{10}$ applied a protocol of aerobic resistance training combined with high intensity, after which a significant increase in the RMSSD index was observed, with no changes in the spectral indices. Borghi-Silva ${ }^{9}$ et al after a 6-week aerobic training protocol, obtained significant increases in the RMSSD index, a decrease in LF, and an increase in HF, analyzed in normalized units. A high level of aerobic fitness has been associated with $\mathrm{HRV}$, probably due to increased vagal activity in controlling the heart rate. ${ }^{9,11}$

In relation to mucociliary clearance, there was no significant difference between periods. This finding corroborates the results found by Salzano et $\mathrm{al}^{7}$ who concluded that aerobic training did not significantly affect mucociliary clearance. The study only demonstrated an acute effect, ie, an increase in mucociliary activity 15 minutes after the aerobic exercise, which can be correlated with increased ventilation and autonomic nervous system activity during the execution of exercise. Nevertheless, this increase was not sustained when analyzed 75 minutes after the training, when it was observed that STT had returned to values close to the initial values.

The chronic effects of aerobic training on mucociliary clearance in patients with COPD are still not well established in the literature. Salh et $\mathrm{al}^{40}$ conducted a study in lung disease patients with cystic fibrosis submitted to aerobic training on an ergometer cycle, and analyzed the quantity of mucus expectoration, which is directly related to mucociliary activity and clearance, after 2 months of home physical training. The results demonstrated weight increases in the collected mucus, although not a significant amount. The results shown by
Salh et $\mathrm{al}^{40}$ were similar to those in the present study as it was not possible to observe any influence of aerobic training on mucociliary clearance in patients with COPD.

Previous studies have demonstrated that patients with COPD presented loss and significant alterations in mucociliary clearance. ${ }^{4,5}$ Afonso et $\mathrm{al}^{4}$ found that the mucus relative velocity of ciliary transport on frog palate was greater in the healthy individuals than in the COPD and bronchiectasis groups: healthy group $=1.0 \pm 0.19$ seconds, COPD group $=0.91 \pm 0.17$ seconds, and bronchiectasis group $=0.76 \pm 0.23$ seconds. $^{4}$

In contrast, such alterations were not detected in the present study, where patients presented preserved mucociliary function with normal baseline values. ${ }^{41}$ It is suggested that these levels are associated with the smoking cessation period of these patients, who were included in this study only after 1 year of smoking abstinence; the patients presented a mean time of 9.5 years without smoking. It is known that there is repair and remodeling of the tissue of the respiratory tract in patients with COPD, although mechanisms for such restructuring are still not clear. ${ }^{42}$ Ramos et $\mathrm{al}^{43}$ found that there is reversibility of mucociliary function in smokers 15 days after smoking abstinence. It is believed that similar mechanisms also occur in patients with COPD. Therefore, smoking cessation is of the utmost importance as a fundamental component of pulmonary rehabilitation programs.

The present proposal of linear periodized aerobic training resulted in significant aerobic improvements, in addition to positively influencing autonomic modulation in patients with COPD. This enriches and provides additional support to discussions on the theme of training modalities for these individuals. Furthermore, the present training proposal consisted of an additional option when compared to other COPD training methods, as it allowed better adaptation of the neuromuscular system to support the burdens imposed by the variations in volume and training intensities. In this way, it differentiates itself from pulmonary rehabilitation programs widely recommended as part of COPD treatment.

\section{Conclusion}

This study concluded that 12-week periodized aerobic training positively influenced autonomic modulation and aerobic power in patients with COPD; however, no effect was observed on mucociliary clearance in these patients.

\section{Limitations}

In contrast to previous studies, the aerobic training applied was composed of both continuous and interval sessions. 
This approach was predominantly chosen because we expected lower levels of monotony due to the decrease in time expended in each zone of training (ie, Z1: "easy" continuous; Z2: "hard" continuous; Z3: "heavy" interval). Thus, we believe that this study contributes to the training prescription applied to COPD patients. However, the main limitation was the high loss of participants in both groups during the experiment, which highlights the need for more studies using this aerobic training prescription.

\section{Acknowledgment}

This work was supported by the following Brazilian Scientific Agency: Fundação de Amparo à Pesquisa do Estado de São Paulo (FAPESP).

\section{Disclosure}

The authors report no conflicts of interest in this work.

\section{References}

1. Andrianopoulos V, Klijn P, Franssen FM, Spruit MA. Exercise training in pulmonary rehabilitation. Clin Chest Med. 2014;35(2):313-322.

2. Reis LF, Guimarães FS, Fernandes SJ, et al. A long-term pulmonary rehabilitation program progressively improves exercise tolerance, quality of life and cardiovascular risk factors in patients with COPD. Eur J Phys Rehabil Med. 2013;49(4):491-497.

3. Wadell K, Webb KA, Preston ME, et al. Impact of pulmonary rehabilitation on the major dimensions of dyspnea in COPD. COPD. 2013;10(4): $425-435$.

4. Afonso JL, Tambascio J, Souza HCD, Jardim JR, Martinez JAB, Gastaldi AC. Transporte de secreções mucóides de indivíduos saudáveis e pacientes com doença pulmonar obstrutiva crónica e bronquiectasias [Transport mucoid secretions of healthy individuals and patients with chronic obstructive pulmonary disease and bronchiectasis]. Rev Port Pneumol. 2013;19(5):211-216. Portuguese.

5. Smaldone GC, Foster WM, O'Riordan TG, Messina MS, Perry RJ, Langenback EG. Regional impairment of mucociliary clearance in chronic obstructive pulmonary disease. Chest. 1993;103:1390-1396.

6. Bhowmik A, Chahal K, Austin G, Chakravorty I. Improving mucociliary clearance in chronic obstructive pulmonary disease. Respir Med. 2009; 103(4):496-502.

7. Salzano FA, Manola M, Tricarico D, Precone D, Motta G. Mucociliary clearance after aerobic exertion in athletes. Acta Otorhinolaryngol Ital. 2000;20(3):171-176.

8. Wolff RK, Dolovich MB, Obminski G, Nousehouse MT. Effects of exercise and eucapnic hyperventilation on bronchial clearance in man. J Appl Physiol. 1977;43(1):46-50.

9. Borghi-Silva A, Arena R, Castello V, et al. Aerobic exercise training improves autonomic nervous control in patients with COPD. Respir Med. 2009;103(10):1503-1510.

10. Camillo CA, Laburu VM, Gonçalves NS, et al. Improvement of heart rate variability after exercise training and its predictors in COPD. Respir Med. 2011;105(7):1054-1062.

11. Leite MR, Ramos EM, Kalva-Filho CA, et al. Correlation between heart rate variability indexes and aerobic physiological variables in patients with COPD. Respirology. 2015;20(2):273-278.

12. Beauchamp MK, Nonoyama M, Goldstein RS, et al. Interval versus continuous training in individuals with chronic obstructive pulmonary disease - a systematic review. Thorax. 2010;65(2):157-164.
13. GOLD. Global strategy for the diagnosis, management, and prevention of chronic obstructive pulmonary disease - revised 2011. Available from: http://www.goldcopd.org/uploads/users/files/GOLD_ Report_2011_Feb21.pdf. Accessed September 21, 2015.

14. Lohman TG, Roche AF, Martorell R. Anthropometric Standardization Reference Manual. Champaign, IL: Human Kinetics Books; 1988.

15. Miller MR, Hankinson J, Brusasco V, et al. Standardisation of Spirometry "ATS/ERS Task Force: Standardisation of Lung Function Testing.” Eur Respir J. 2005;26:319-338.

16. Duarte AA, Pereira CAC, Rodrigues SC. Validation of new Brazilian predicted values for forced spirometry in caucasians and comparison with predicted values obtained using other reference equations. J Bras Pneumol. 2007;33(5):527-535.

17. Borghi-Silva A, Baldissera V, Sampaio LM, et al. L-carnitine as an ergogenic aid for patients with chronic obstructive pulmonary disease submitted to whole-body and respiratory muscle training programs. Braz J Med Biol Res. 2006;39(4):465-474.

18. Kendrick KR, Baxi SC, Smith RM. Usefulness of the modified 0-10 Borg scale in assessing the degree of dyspnea in patients with COPD and asthma. J Emerg Nurs. 2000;26(3):216-222.

19. Kuipers H, Verstappen FTJ, Keizer, HA, Guerten P, Van Kranenburg G. Variability of anaerobic performance in the laboratory and its physiologic correlates. Int J Sports Med. 1985;6(4):197-201.

20. Sue DY, Wasserman K, Moricca RB, Casaburi R. Metabolic acidosis during exercise in patients with chronic obstructive pulmonary disease. Chest. 1988;94:931-938

21. Vanderlei LCM, Silva RA, Pastre CM, Azevedo FM, Godoy MF. Comparison of the Polar S810i monitor and the ECG for the analysis of heart rate variability in the time and frequency domains. Braz J Med Biol Res. 2008;41(10):854-859.

22. Task Force of the European Society of Cardiology and the North American Society of Pacing and Electrophysiology. Heart rate variability: standards of measurement, physiological interpretation, and clinical use. Circulation. 1996;93:1043-1065.

23. Godoy MF, Takakura IT, Correa PR. The relevance of nonlinear dynamic analysis (Chaos theory) to predict morbidity and mortality in patients undergoing surgical myocardial revascularization. Arch Health Sci. 2005;12(4):167-171.

24. Moreno IL, Pastre CM, Ferreira C, de Abreu LC, Valenti VE, Vanderlei LC. Effects of an isotonic beverage on autonomic regulation during and after exercise. J Int Soc Sports Nutr. 2013;10(1):2.

25. Tarvainen MP, Niskanen JA, Lipponen PO, Ranta-aho PO, Karjalainen PA. Kubios HRV - a software for advanced heart rate variability analysis. In: Sloten JV, Verdonck P, Nyssen M, Haueisen J, editors. 4th European Conference of the International Federation for Medical and Biological Engineering. Berlin: Springer; 2008: 1022-1025.

26. Salah B, Xuan Dihn AT, Fouilladieu JL, Lockhart A, Regnard J. Nasal mucociliary transport in healthy subjects is slower when breathing dry air. Eur Respir J. 1988;1:852-855.

27. Andersen IB, Camner P, Jensen PL, Philipson K, Proctor DF. A comparison of nasal and tracheobronchial clearance. Arch Environ Health. 1974;29(5):290-293.

28. Nicola ML, Carvalho HB, Yoshida CT, et al. Young "healthy" smokers have functional and inflammatory changes in the nasal and the lower airways. Chest. 2014;145(5):998-1005.

29. Esteve-Lanao J, Foster C, Seiler S, Lucia A. Impact of training intensity distribution on performance in endurance athletes. J Strength Cond Res. 2007;21(3):943-939.

30. Muñoz I, Seiler S, Bautista J, España J, Larumbe E, Esteve-Lanao J. Does polarized training improve performance in recreational runners? Int J Sports Physiol Perform. 2014;9(2):265-272.

31. Stellingwerff T. Case study: nutrition and training periodization in three elite marathon runners. Int J Sport Nutr Exerc Metab. 2012;22(5): $392-400$. 
32. Bragada JA, Santos PJ, Maia JA, et al. Longitudinal study in 3,000 m male runners: relationship between performance and selected physiological parameters. J Sports Sci Med. 2010;9(3):439-444.

33. Wasserman K, Whipp BJ, Koyal SN, Beaver WL. Anaerobic threshold and respiratory gas exchange during exercise. J Appl Physiol. 1973;35: 236-243.

34. Bertuzzi RCM, Silva AEL, Abad CC, Pires FO. Metabolismo do lactato: uma revisão sobre a bioenergética e a fadiga muscular [Lactate metabolism: a review of bioenergetics and muscle fatigue]. Rev Bras Cineantrop Des Hum. 2009;11(21):226-234. Portuguese.

35. Caputo F, De Oliveira MFM, Greco CC, Denadai BS. Exercício aeróbio: aspectos bioenergéticos, ajustes fisiológicos, fadiga e índices de desempenho [Aerobic exercise: bioenergetics, physiological adjustments, fatigue and performance indices]. Rev Bras Cineantrop Des Hum. 2009;11(1):94-102. Portuguese.

36. Hsieh MJ, Lan CC, Chen NH, et al. Effects of high-intensity exercise training in a pulmonary rehabilitation programme for patients with chronic obstructive pulmonary disease. Respirology. 2007;12(3): 381-388.

37. van Helvoort HA, de Boer RC, van de Broek L, Dekhuijzen R, Heijdra YF. Exercises commonly used in rehabilitation of patients with chronic obstructive pulmonary disease: cardiopulmonary responses and effect over time. Arch Phys Med Rehabil. 2011;92(1):111-117.
38. Spruit MA, Gosselink R, Troosters T, De Paepe K, Decramer M. Resistance versus endurance training in patients with COPD and peripheral muscle weakness. Eur Respir J. 2002;19(6):1072-1078.

39. Vanderlei LCM, Pastre CM, Hoshi RA, Carvalho TD, Godoy F. Noções básicas de variabilidade da frequência cardíaca e sua aplicabilidade clínica [Basics of heart rate variability and its clinical applicability]. Rev Bras Cir Cardiovasc. 2009;24(2):205-217. Portuguese.

40. Salh W, Bilton D, Dodd M, Webb AK. Effect of exercise and physiotherapy in aiding sputum expectoration in adults with cystic fibrosis Thorax. 1989;44(12):1006-1008.

41. Nakagawa NK, Franchini ML, Driusso P, de Oliveira LR, Saldiva PH, Lorenzi-Filho G. Mucociliary clearance is impaired in acutely ill patients. Chest. 2005;128(4):2772-2777.

42. Ganesan S, Sajjan US. Repair and remodeling of airway epithelium after injury in chronic obstructive pulmonary disease. Curr Respir Care Rep. 2013;2(3):145-154.

43. Ramos EM, De Toledo AC, Xavier RF, et al. Reversibility of impaired nasal mucociliary clearance in smokers following a smoking cessation programme. Respirology. 2011;16(5):849-855.
International Journal of COPD

\section{Publish your work in this journal}

The International Journal of COPD is an international, peer-reviewed journal of therapeutics and pharmacology focusing on concise rapid reporting of clinical studies and reviews in COPD. Special focus is given to the pathophysiological processes underlying the disease, intervention programs, patient focused education, and self management protocols.

\section{Dovepress}

This journal is indexed on PubMed Central, MedLine and CAS. The manuscript management system is completely online and includes a very quick and fair peer-review system, which is all easy to use. Visit http://www.dovepress.com/testimonials.php to read real quotes from published authors. 